\title{
COMPARISON OF DEBURRING TECHNOLOGIES AFTER PIPE CUTTING
}

\author{
${ }^{1}$ Radek ČADA, ${ }^{1}$ Pavel LOŠÁK \\ ${ }^{1}$ VSB - Technical University of Ostrava, Ostrava, Czech Republic,EU, radek.cada@vsb.cz
}

https://doi.org/10.37904/metal.2021.4161

\begin{abstract}
In the article, the technologies of deburring after pipe cutting are analyzed. The pipe cutting technologies and the external or internal burrs that are formed are described. The criteria of maximum productivity, minimum cost and maximum process stability were chosen for the comparison of the technologies of deburring of pipe ends. Since the essential advantage of both brushing and plastering technologies is the independence of the deburring process from the geometric accuracy of the pipe ends, a more detailed analysis of the two technologies and their mutual comparison was carried out. For the cost analysis of these technologies, pipes with a wall thickness of $0.6 \mathrm{~mm}$ and a production batch of 5,000 pieces were selected. Based on the analysis, it can be concluded that for the operation of deburring of split pipe surfaces, the plastering technology is preferable to the brushing method, within the range of possible technological applications. It is appropriate to use the brushing technology as a secondary technology for deburring the ends of pipes for which it is not possible or appropriate to use the plastering technology.
\end{abstract}

Keywords: Burr, cutting, pipe, brushing, plastering

\section{INTRODUCTION}

In passenger cars, aircraft, buildings, air conditioning, etc., there are systems of ducts that consist of pipes. Pipes are used for transporting liquids, gases or other media. There are usually requirements for their resistance to corrosion and ageing, and possibly resistance to high operating temperatures or pressures. The starting material for the production of pipes is strip steel, usually produced by continuous casting [1], rolled cold in the form of coils. One option for producing corrosion-resistant components is the use of hot-dip galvanised blanks [2]. They are mainly used in the automotive industry. The mechanical properties of sheet metal can be increased in some applications, e.g. by the unconventional forming method DRECE (Dual Rolls Equal Channel Extrusion) [3]. The strip steel is progressively curved in the line. For forming, the material must have sufficient formability [4,5]. The method of deformation networks can be used to analyze the deformation during forming [6]. The bent strip steel is subsequently welded. The welding technology affects the deformation properties of the steel [7] as well as the corrosion resistance. After subsequent calibration, the pipe is cut [8] and, if necessary, bent to the desired shape. For the stability of the production process, machine maintenance must be managed, preferably using productive maintenance [9]. Achieving maximum production productivity while eliminating any wastage can be achieved, for example, by using the Value Stream Mapping method [10].

\section{PIPE CUTTING AND BURR FORMATION}

The following technologies can be used for pipe cutting:

a) cutting with an internal disc knife and an external knife (A single-purpose machine is used. The inner disc knife is clamped in a spindle with defined speed, rotates around its axis and continuously increases the radius it describes. The advantage of the method is minimal waste and high productivity),

b) shearing (using a circular knife and an internal mandrel on the lathe), 
c) punching on the lathe (the advantage is the high cutting accuracy),

d) band sawing (the cutting gap is usually one to two thirds smaller than with circular or frame saws, the cutting surface has a high surface quality).

The burrs resulting from pipe cutting can be divided into:

a) burrs produced on the outer edge of the pipe, by the action of the tool from the centre of the pipe axis towards the outer surface of the pipe (cutting with an internal circular knife and an external knife),

b) burrs produced on the inner edge of the pipe by the action of the tool from the outer surface of the pipe towards the axis of the pipe (cutting or punching on the lathe),

c) burrs on the inner and outer edges of the pipe caused by cutting with a band saw.

\section{TECHNOLOGIES FOR DEBURRING AFTER PIPE CUTTING}

\subsection{Use of the modified countersink}

A countersink designed for countersinking holes can be machined by creating a hole in its axis along its entire length. Through this hole, compressed air flows towards the mandrel, through which it flows backwards on the outside to remove the metal chips that have formed. The modified countersink (Figure 1) is clamped in a machine holder which creates a rotary movement of the countersink around its axis. It is used after cutting the pipes on the lathe by shearing (using a circular knife and an internal mandrel) to remove burrs on the inside of the pipes.

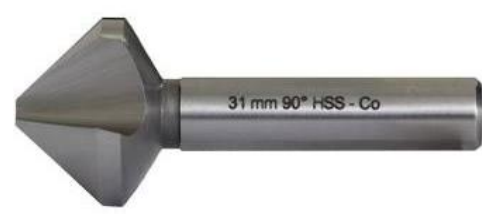

Figure 1 Countersink for removing internal burrs at pipe ends

\subsection{Deburring with a technical milling cutter}

This is the use of a powered technical milling cutter (Figure 2) designed for manual machining. to use this technology correctly, it is necessary to install a backing plate that is perpendicular to the axis of the rotating tool. in this plate, there is a hole of adequate size for the technical milling cutter to be repositioned to the plane of the support plate. by resting the end of the pipe against the backing plate, the perpendicularity of the face of the hole to the tool is ensured. This method can be used for pipes with larger end diameters that are to be free of internal burrs.

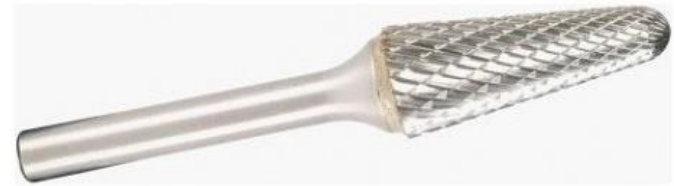

Figure 2 Technical milling cutter for deburring internal burrs on pipe ends

\subsection{Deburring using a pipe deburring machine}

The rotary motion of the tool is used to remove the external burr from the pipe. The technology is characterized by its high productivity and reliability. After tool change, a deburring machine (e.g. Transfluid RE $642 \mathrm{a}$ - see Figure 3) can also be used to remove internal burrs. When deburring larger pipe diameters (greater than $40 \mathrm{~mm}$ ), the use of experienced operators is advisable due to the increased skill requirements.

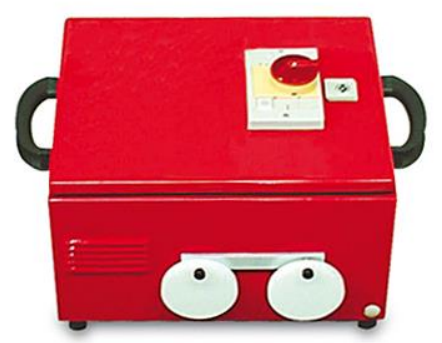

Figure 3 Pipe deburring machine Transfluid RE 642 A

\subsection{Deburring by brushing}

Brushing is suitable for removing burrs on the outer edge of the pipe end. At the same time, on the area 4 to $5 \mathrm{~mm}$ from the edge of the pipe, the dirt is removed evenly, increasing the uniformity of the surface and reducing possible unevenness that would have a negative effect in subsequent operations when creating 
individual assemblies. The tool is mounted on the shaft of the grinding machine and its speed can be controlled. The operator performing this operation should be sufficiently trained and involved to avoid any discrepancies.

\subsection{Removal of burrs by plastering}

The technology of plastering mechanically modifies the surface of the material by mutual abrasion of objects, plastering bodies, abrasive and liquid in a rotating bell or drum. Rendering is a technology particularly well suited for smaller objects with rounded curves and geometries. The main advantages of plastering include avoiding physically strenuous and unhygienic manual grinding and polishing, optimizing production costs, increasing production rates, reducing scrap and hardening the plastered surface in parallel with increasing corrosion resistance. The main disadvantage of plastering is the uneven removal from the product surfaces, with the greatest removal occurring at the edges, resulting in the likelihood of damage to rugged products.

\section{CRITERIA SUITABLE FOR COMPARING DEBURRING TECHNOLOGIES AFTER CUTTING}

The following criteria can be used to compare deburring technologies after cutting:

a) maximum productivity (enables timely delivery to customers),

b) minimum costs (minimization of resources spent by the company during the production process, minimization of material consumption and thus achieving minimization of waste),

c) maximum process stability (avoiding undue scrap or deterioration in the quality of manufactured parts that would adversely affect productivity and production costs).

\section{COMPARISON OF BRUSHING AND PLASTERING TECHNOLOGIES}

A significant advantage of both brushing and plastering technologies is the independence of the deburring process from the geometric accuracy of the pipe ends. For this reason, a more detailed analysis of the two technologies and their mutual comparison is made below. The comparison has been made on pipes cut by an inner disc knife, which performs a spiral motion and presses the pipe from the inside to the outer knife, i.e. The burr is formed on the outside of the pipe.

\subsection{Brushing technology}

For the analysis of the brushing technology, a pipe with an outer diameter of $15 \mathrm{~mm}$, a wall thickness of $0.6 \mathrm{~mm}$ and a length of the connecting line between the hole centres of $140.5 \mathrm{~mm}$ (Figure 4) made of material 1.4541 was used. The work cycle consists of brushing the burrs at both ends of the pipe, thus involving the processing of one component. The grinding roll used to remove the outer burrs at the ends of the pipes is shown in Figure 5.
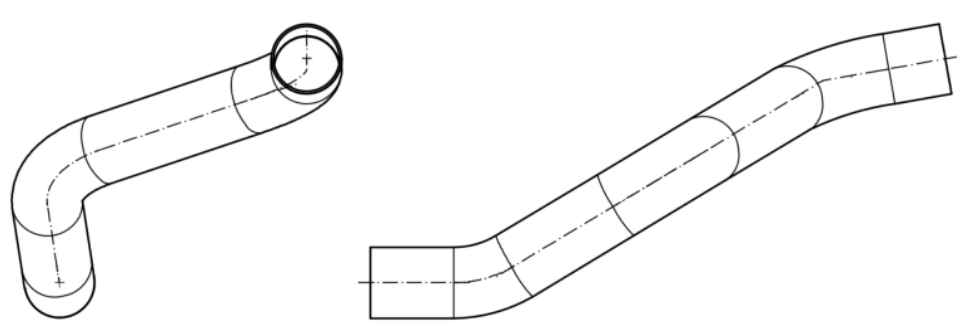

Figure 4 Pipe deburred by brushing

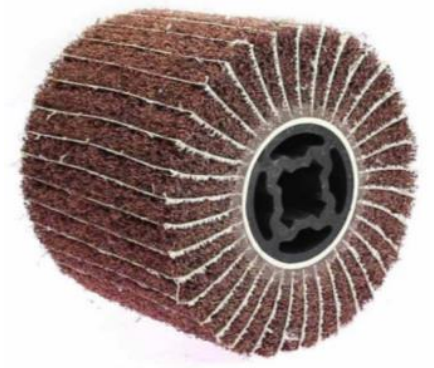

Figure 5 Grinding roller used for removing external burrs on pipe ends 
The analysis used a standard time consumption value for this technology of 0.25 minutes per piece. The work cycle is smooth, with no unnecessary downtime, with 10 minutes required for workstation preparation and adjustment of production tools. This preparation takes place only once, at the beginning of a production run of 5,000 pieces. The overhead cost of the brushing technology is $300 \mathrm{CZK}$ per hour (i.e. $5 \mathrm{CZK}$ per minute). This overhead includes staff costs and consumption of working materials.

Cost of brushing technology for the entire production batch:

$N_{\mathrm{k}}=\left(t_{\mathrm{pk}}+t_{\mathrm{jk}} \cdot p_{\mathrm{c}}\right) \cdot R_{\mathrm{vk}}=(10+0.25 \cdot 5,000) \cdot 5=6,300 \mathrm{CZK}$

where:

$t_{\mathrm{pk}}$ - preparation time for brushing method (min.), 10 minutes inserted,

$t_{\mathrm{k} k}$ - time for deburring one pipe by brushing (min.), $0.25 \mathrm{~min}$. inserted,

$p_{c}-$ total number of parts in the production batch (-), 5,000 pcs inserted,

$R_{\mathrm{vk}}$ - overheads of production using brushing technology (CZK $\left.\cdot \mathrm{min}^{-1}{ }^{-1}\right), 5 \mathrm{CZK} \cdot \mathrm{min}^{-1}{ }^{-1}$ inserted.

Amount of pipes processed by brushing per 60 minutes of production time (excluding preparation times):

$p_{\mathrm{hk}}=\frac{60}{t_{\mathrm{jk}}}=\frac{60}{0.25}=240 \mathrm{pcs}$

\subsection{Plastering technology}

A vibratory plastering machine CF 300 from Walther Trowal was selected to assess the plastering technology (Figure 6). The vibrating vessel works on the principle of vibration by vibrators. This reduces the processing time by up to $50-70 \%$ compared to tumbling. There is also less chance of damage-prone products. The vibrating machine is equipped with two working speeds. For separation of the parts to be plastered, the vibratory machine is equipped with a pneumatic separating flap with a separation zone. The specifications of the CF vibratory machine from Walter Trowal are shown in Table 1. Ceramic abrasive bodies (Figure 7) are used for plastering, which removes the burr on the cut end of the pipe in a suitable stepwise manner. These rollers are $12 \mathrm{~mm}$ in diameter and $30 \mathrm{~mm}$ long.

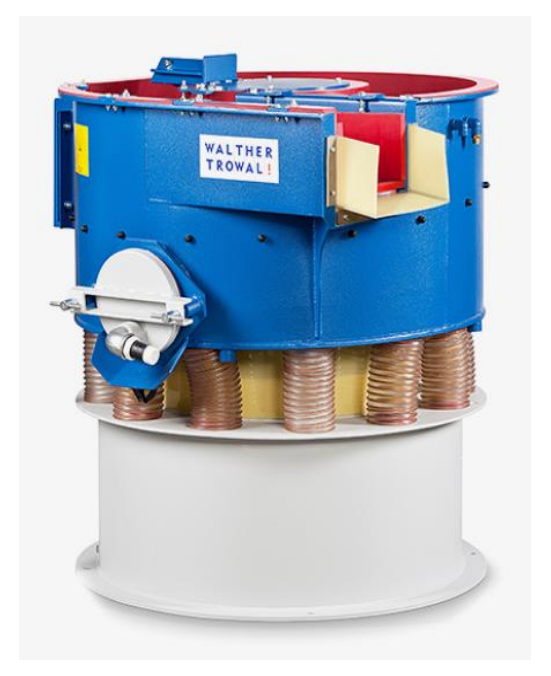

Figure 6 Vibrating machine CF 300 from Walther Trowal
Table 1 Technical parameters of vibrating plastering machine CF 300 from Walther Trowal

\begin{tabular}{|l|l|}
\hline Gross volume of the working vessel & $300 \mathrm{I}$ \\
\hline Usable volume of the working vessel & $190 \mathrm{I}$ \\
\hline Largest product dimension measured diagonally & $220 \mathrm{~mm}$ \\
\hline Total size of the separation area & $271,000 \mathrm{~mm}^{2}$ \\
\hline Total weight & $1,020 \mathrm{~kg}$ \\
\hline Power input at $1,500 \mathrm{rpm}$ & $2.6 \mathrm{~kW}$ \\
\hline
\end{tabular}

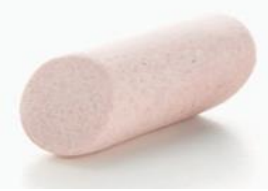

Figure 7 Ceramic grinding wheel

A pipe with an outer diameter of $25.1 \mathrm{~mm}$, a wall thickness of $0.6 \mathrm{~mm}$, and a joint length between hole centres of $143 \mathrm{~mm}$ (Figure 8) made of 1.4541 was used for the analysis of the plastering technology. The deburring 
of these pipes is carried out in cycles of 30 minutes, with the first 20 minutes being the actual deburring time and the following 10 minutes being spent by the vibratory deburring machine operator removing the deburred pipes and then loading the deburred pipes into the vibratory vessel to repeat the production cycle. in one production cycle, 250 pieces of pipes are plastered. The set-up time of the vibratory plastering machine is 5 minutes and is only done once, at the beginning of a production run of 5,000 pieces. The overhead cost of the plastering technology is $340 \mathrm{CZK}$ per hour (i.e. 5.67 CZK per minute). This overhead includes the cost of employees and the consumption of working materials.

Time for deburring a single pipe by plastering (including preparation times):

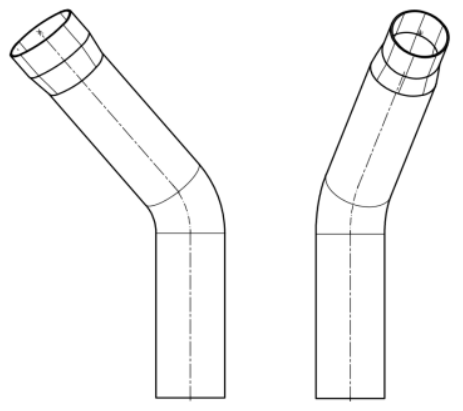

Figure 8 Pipe deburred by plastering

$t_{\mathrm{jo}}=\frac{t_{\mathrm{o}}}{p_{\mathrm{o}}}=\frac{30}{250}=0.12 \mathrm{~min}$.

where:

$t_{0}$ - time of one cycle of plastering ( $\left.\min .\right), 30$ minutes inserted,

$p_{0}-$ number of plastered parts (-), 250 pcs inserted.

Cost of coating technology for the entire production batch:

$N_{\mathrm{o}}=\left(t_{\mathrm{po}}+t_{\mathrm{jo}} \cdot p_{\mathrm{c}}\right) \cdot R_{\mathrm{vo}}=(5+0.12 \cdot 5,000) \cdot 5.67=3,430.35 \mathrm{CZK}$

where:

$t_{\mathrm{po}}-$ preparation time for the plastering (min.), 5 minutes inserted,

$t_{\mathrm{j} o}$ - time for deburring one pipe by plastering ( $\left.\min .\right), 0.12$ minutes inserted,

$p_{c}-$ total number of parts in the production batch (-), 5,000 pcs inserted,

$R_{v o}$ - overheads of production using plastering $\left(\mathrm{CZK} \cdot \mathrm{min}^{-1}\right), 5.67 \mathrm{CZK} \cdot \mathrm{min}^{-1}{ }^{-1}$ inserted.

Quantity of pipes processed by plastering per 60 minutes of production time (excluding preparation times):

$p_{\mathrm{ho}}=\frac{60}{t_{\mathrm{jo}}}=\frac{60}{0.12}=500 \mathrm{pcs}$

The values calculated from equations (1) to (5) are summarized in Table 2.

Table 2 Comparison of brushing and plastering technologies by productivity and cost

\begin{tabular}{|c|c|c|c|}
\hline $\begin{array}{c}\text { Deburring technology } \\
\text { used }\end{array}$ & $\begin{array}{c}\text { Production } \\
\text { in } \mathbf{6 0} \text { min. (-) }\end{array}$ & $\begin{array}{c}\text { Deburring time for 1 pipe } \\
\text { (min.) }\end{array}$ & $\begin{array}{c}\text { Overheads for a production } \\
\text { batch of 5000 pcs (CZK) }\end{array}$ \\
\hline Brushing & 240 & 0.25 & $6,300.0$ \\
\hline Plastering & 500 & 0.12 & $3,430.4$ \\
\hline
\end{tabular}

\section{EVALUATION OF DEBURRING BY BRUSHING OR PLASTERING}

In terms of both productivity and cost, plastering technology is more than twice as advantageous (see Table 2) as brushing technology. Plastering technology is characterized by very low numbers of poorly deburred pipe ends, resulting in high process stability

The disadvantage of plastering is that it is not suitable for plaster pipes with very small wall thicknesses because of possible edge deformation at the ends of the pipe. Minimum wall thicknesses vary according to the material used and the design of the product. For material 1.4541 and the type of pipe used in Chapter 5 
(see Figure 4 and Figure 8), the minimum wall thickness is $0.4 \mathrm{~mm}$. at the same time, the maximum diagonal dimension of the part that can be plastered $(220 \mathrm{~mm}$ in the case of the CF 300 vibratory plastering machine) must be observed. a complication can be the customer's requirement to achieve a uniform appearance, which is difficult to maintain in bent areas of pipes.

In brushing technology, the work of the machine operator has a great influence on the likelihood of the occurrence of insufficiently removed burrs on split pipe ends, due to the higher demands on skill and responsibility compared to plastering technology.

After both technologies have been used to remove burrs at the ends of the pipes, the pipes are cleaned (removing grease, dirt and foreign bodies) by washing them in a dishwasher. In the case of liming, more frequent changes of the cleaning bath must be taken into account than in the case of the cleaning of deburred pipes by brushing. This is due to the higher incidence of working material (ceramic body residues) trapped in the deburred tubes by plastering.

\section{CONCLUSION}

Based on the analysis, it can be concluded that to achieve maximum productivity, minimum costs and maximum process stability, it is preferable to use the plastering technology rather than the brushing method for the deburring operation on the split pipe surfaces, within the range of possible technological applications. It is not advisable to plaster pipes of very small wall thicknesses because of possible edge deformation at the ends of the pipe. The maximum diagonal dimension of the part that can be plastered should also be taken into account. Customers' requirements sometimes include achieving a uniform appearance, which cannot be achieved with more complicated shapes by plastering technology. Brushing technology should therefore be used as a secondary technology to remove burrs at the ends of pipes where plastering technology is not possible or appropriate.

\section{ACKNOWLEDGEMENTS}

\section{Results were achieved at solving the specific research project No. SP2021/104 at the Faculty of Mechanical Engineering of VSB - Technical University of Ostrava.}

\section{REFERENCES}

[1] VELIČKA, M. et al. Research of Thermal Processes for the Continuous Casting of Steel. Materiali in Tehnologije. 2013, vol. 47, no. 6, pp. 815-818. ISSN 1580-2949.

[2] VONTOROVÁ, J., MOHYLA, P. Use of GDOES Method for Evaluation of the Quality and Thickness of Hot Dip Galvanised Coating. Transactions of the Institute of Metal Finishing. [online]. 2018, vol. 96, no. 6, pp. 313-318. Available from: https://doi.org/10.1080/00202967.2018.1520531.

[3] HILŠER, O., RUSZ, S., SALAJKA, M., ČížEK, L. Evaluation of the Deep-Drawing Steel Sheets Processed by DRECE Device. Archives of Materials Science and Engineering. 2014, vol. 68, no. 1, pp. 31-35. ISSN 18972764.

[4] NOVÁK, V., VALEŠ, M., TATÍČEK, F., ŠANOVEC, J., CHRÁŠŤANSKÝ, L. The Effect of Strain Rate on Position of Forming Limit Curve. In: $28^{\text {th }}$ International Conference on Metallurgy and Materials (Metal 2019). [online]. Ostrava, Czech Republic: TANGER, 2018, pp. 378-383. Available from:https://doi.org/10.37904/metal.2019.825.

[5] EVIN, E., TOMÁŠ, M., VÝBOCH, J. Prediction of Local Limit Deformations of Steel Sheets Depending on Deformation Scheme. Chemical Journal. 2012, vol. 106, S3, pp. 401-404. ISSN 0009-2770.

[6] ČADA, R. Testing of Strain in Stampings by Embossed Grids. Technical Gazette. 2003, vol. 10, no. 3-4, pp. 9-13. ISSN 1330-3651.

[7] EVIN, E., TOMÁŠ, M., VÝROSTEK, M. Laser-Beam Welding Impact on the Deformation Properties of Stainless Steels when Used for Automotive Applications. Acta Mechanica Automatica, [online]. 2016, vol. 10, no. 3, pp. 189-194. ISSN 1898-4088. Available from: https://doi.org/10.1515/ama-2016-0028. WOS:000408719000004. 
[8] LOŠÁK, P. Analysis of Deburring Technologies after Cutting the Material: Bachelor Thesis. Ostrava: VŠB-TUO, 2021, p. 53.

[9] NEČAS, L. Training and Practice to Ensure Implementation of the TPM System. Modern Machinery (MM) Science Journal. [online]. June 2019, vol. 12, no. 2, pp. 4124-4127. ISSN 1803-1269 (Print), ISSN 1805-0476 (On-line). Available from: https://doi.org/10.17973/MMSJ.2020 112020043.

[10] ŠAJDLEROVÁ, I., GREGUŠOVÁ, M., SCHINDLEROVÁ, V. Potential of Value Stream Mapping Utilization in the Seamless Steel Pipes Manufacturing Process. In: $24^{\text {th }}$ International Conference on Metallurgy and Materials (Metal 2015). Ostrava, Czech Republic: TANGER, 2015, pp. 2056-2064. ISBN 978-80-8729462-8. 